\title{
Magnetism of $\mathrm{CoFe}_{2} \mathrm{O}_{4}$ ultrathin films on $\mathrm{MgAl}_{2} \mathrm{O}_{4}$ driven by epitaxial strain
}

\author{
C. Gatel, ${ }^{1}$ B. Warot-Fonrose, ${ }^{1}$ S. Matzen, ${ }^{2}$ and J.-B. Moussy ${ }^{2}$ \\ ${ }^{1}$ CEMES-CNRS, F-31055 Toulouse, France \\ ${ }^{2}$ CEA-Saclay, IRAMIS, SPCSI, 91191 Gif-Sur-Yvette, France
}

(Received 23 June 2013; accepted 9 August 2013; published online 27 August 2013)

\begin{abstract}
We report on the correlations between magnetic anisotropy and strain state in $\mathrm{CoFe}_{2} \mathrm{O}_{4}$ ultrathin films grown on $\mathrm{MgAl}_{2} \mathrm{O}_{4}(100)$ and $\mathrm{MgAl}_{2} \mathrm{O}_{4}(111)$ substrates. By local strain analysis using the geometric phase method, a significant in-plane compressive strain is observed for the (001) orientation while a full relaxation is detected for the (111) orientation. The relaxation process in $\mathrm{CoFe}_{2} \mathrm{O}_{4}(111)$ layers induces interface dislocations and a large amount of antiphase boundaries while a pseudomorphic growth is observed for the (001) direction, decreasing significantly the density of antiphase boundaries. By comparing the magnetoelastic energy terms, the correlation between strain state and resultant magnetization is discussed. (C) 2013 AIP Publishing LLC.

[http://dx.doi.org/10.1063/1.4819178]
\end{abstract}

The relationship between strain and magnetism has gained considerable interest with the study of multiferroic materials, which present two coupled properties among ferromagnetism (or anti-ferromagnetism), ferroelectricity, and ferroelasticity. ${ }^{1}$ Very few materials are intrinsically multiferroic, the most studied being $\mathrm{BiFeO}_{3}$, but extrinsic multiferroic materials have been proposed. They combine, for example, a magnetostrictive material with a ferroelastic one. ${ }^{2}$ Magnetic oxides are of particular interest, especially cobalt ferrite $\left(\mathrm{CoFe}_{2} \mathrm{O}_{4}\right)^{3}$ that presents the highest magnetostriction coefficient reported, ${ }^{4,5}$ offering the capability of mastering the magnetization with strain.

Magnetic properties of spinel ferrites are often modified when these oxides are deposited as thin films (decrease of magnetization, Curie temperature, or coercive field). In order to understand and optimize the magnetism in thin films, it is particularly important to study the local defects (cationic ordering, antiphase boundaries), ${ }^{6-8}$ the films strain state (induced by a given substrate and growth mode), and their effects on the magnetic properties. The magnetoelastic effect, corresponding to the correlation between strain and magnetism, has been studied in theoretical work, ${ }^{9,10}$ where the direction of the easy magnetic axis is shown to be tuned by strain. If $\mathrm{CoFe}_{2} \mathrm{O}_{4}$ (cubic lattice parameter $\mathrm{a}_{\mathrm{CoFe} 2 \mathrm{O} 4}$ $=0.8392 \mathrm{~nm}$ ) is under tensile strain, the magnetization will remain out-of-plane whereas a compressive strain will lead to an in-plane magnetization. Experimentally, the easiest way of applying strain to a thin oxide film is to deposit the film epitaxially on a suitable substrate.

Many groups have worked on the deposition of $\mathrm{CoFe}_{2} \mathrm{O}_{4}$ layers on different substrates as for example $\alpha-\mathrm{Al}_{2} \mathrm{O}_{3},{ }^{11}$ $\mathrm{SrTiO}_{3},{ }^{12-16}$ and mostly $\mathrm{MgO} .{ }^{15-19}$ On $\mathrm{SrTiO}_{3}\left(_{\mathrm{SrTiO}}\right.$ $=0.3905 \mathrm{~nm}$ ), the lattice mismatch between the film and the perovskite substrate reaches $+7.45 \%$ (substrate taken as reference), and this compressive strain induces an in-plane easy axis. ${ }^{12,14}$ On the other hand, the small lattice mismatch of $-0.36 \%$ on a rocksalt $\mathrm{MgO}$ substrate $\left(\mathrm{a}_{\mathrm{MgO}}=0.4212 \mathrm{~nm}\right)$ produces an out-of-plane magnetization due to tensile strain. ${ }^{18}$ Few groups have deposited $\mathrm{CoFe}_{2} \mathrm{O}_{4}$ layers on a $\mathrm{MgAl}_{2} \mathrm{O}_{4}$ spinel substrate $\left(\mathrm{a}_{\mathrm{MgAl} 2 \mathrm{O} 4}=0.8083 \mathrm{~nm}\right)$ with striking results. ${ }^{4,5,19}$ On this substrate, $\mathrm{CoFe}_{2} \mathrm{O}_{4}$ films can be completely strained despite a lattice mismatch of $3.82 \%$, undergoing a high in-plane compression of $3.68 \%$, compared to $\mathrm{CoFe}_{2} \mathrm{O}_{4}$ bulk parameter. Even if the reported results confirm in most cases the theoretical predictions, the influence of the magnetoelastic effect is not straightforward due to the complex crystallographic structure of $\mathrm{CoFe}_{2} \mathrm{O}_{4}$.

In this study, we present the epitaxial growth by oxygen-assisted molecular beam epitaxy and the magnetic properties of $\mathrm{CoFe}_{2} \mathrm{O}_{4}$ ultrathin films (5 nm-thick) on $\mathrm{MgAl}_{2} \mathrm{O}_{4}$ substrates for two different crystallographic orientations $((001)$ and (111)). The parameters for the deposition, detailed in a previous paper, ${ }^{11}$ were exactly the same for the two kinds of orientations, allowing to keep the identical inversion parameter for both layers, measured as 0.9 (Ref. 19) (respectively 0.84, data not shown) for (001) (respectively (111)) oriented $\mathrm{CoFe}_{2} \mathrm{O}_{4}$ films, in agreement with the inverse spinel structure predicted by calculation. ${ }^{20}$ The strain state was determined locally using quantitative high resolution transmission electron microscopy (HRTEM). HRTEM observations were performed using a $200 \mathrm{kV}$ FEI Tecnai microscope equipped with a field emission gun and a Cs corrector which avoids delocalization effects at interfaces (point resolution of $0.12 \mathrm{~nm}$ ). A significant portion allowing for a detailed analysis representing the entirety of these samples has been observed. The geometric phase method ${ }^{21}$ has been applied on different HRTEM micrographs to measure the local displacements and strain fields in the ferrite layers compared to the substrates. Thin samples were prepared in cross-sectional geometry using the usual mechanical polishing and a precision ion polishing system to achieve the electron transparency.

Figure 1(a) reports a HRTEM image of a $\mathrm{CoFe}_{2} \mathrm{O}_{4}$ layer on a $\mathrm{MgAl}_{2} \mathrm{O}_{4}(001)$ substrate studied along the [100] zone axis. This micrograph confirms the high quality of the epitaxial growth in the [001] direction as already observed in a previous paper. ${ }^{19}$ The orientation relationships deduced from our HRTEM experiments are $\mathrm{CoFe}_{2} \mathrm{O}_{4}[100](001) / /$ $\mathrm{MgAl}_{2} \mathrm{O}_{4}[100](001)$. In addition, the interface appears perfectly flat without any noticeable interface phase at the atomic scale. The HRTEM experiments performed on different cross sections have revealed a sharp decrease of the 

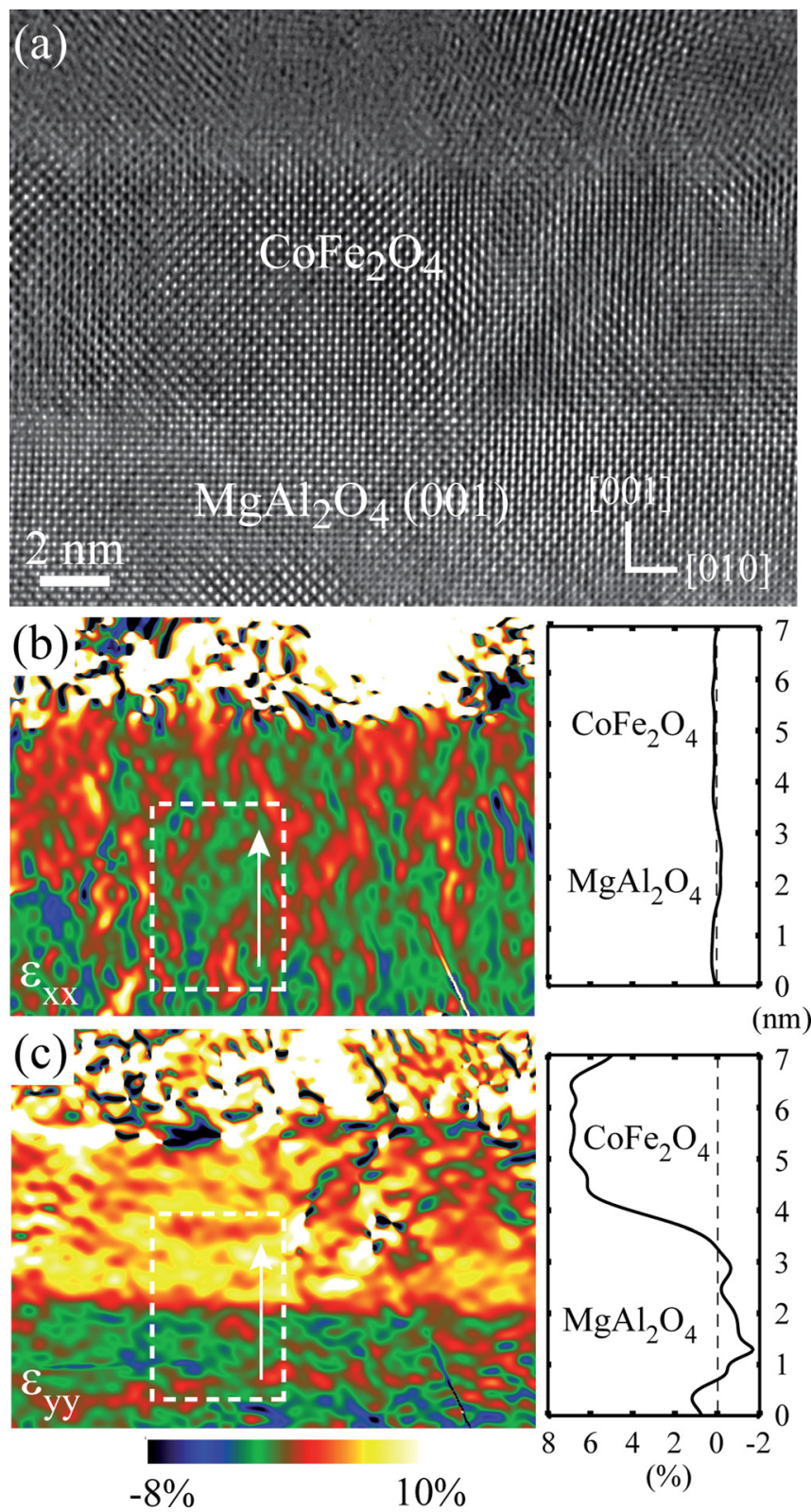

FIG. 1. HRTEM image of a $\mathrm{CoFe}_{2} \mathrm{O}_{4}(001)$ film deposited on $\mathrm{MgAl}_{2} \mathrm{O}_{4}(001)$ (a) with the corresponding geometrical phase analysis for the in-plane deformation $\varepsilon_{x x}$ (b) and the out-of-plane deformation $\varepsilon_{y y}$ (c). Profile of the deformation in dashed rectangle is reported for each direction.

density of antiphase boundaries (APBs). In Figures 1(b) and 1(c) are reported the geometric phase analyses of the strain field in the $\mathrm{CoFe}_{2} \mathrm{O}_{4}(001)$ layer based on the HRTEM image on top. As the reference area is taken within the substrate far from the interface, the measured deformation corresponds to the variation of the interreticular distances with the $\mathrm{MgAl}_{2} \mathrm{O}_{4}$ ones. In the following, $x$ designs the [010] in-plane direction and $y$ is the [001] out-of-plane direction or growth direction. The colour map corresponding to the in-plane deformation $\left(\delta_{x x}\right)$ presents the same colour on the entire thickness of the layer/substrate system, indicating a continuity of the atomic planes between the layer and the substrate (Fig. 1(b)). The profile of this deformation on the right hand side proves the absence of deformation in the $\mathrm{CoFe}_{2} \mathrm{O}_{4}$ layer compared to the substrate $\left(\delta_{x x}=0 \%\right)$ indicating a fullstrained $\mathrm{CoFe}_{2} \mathrm{O}_{4}$ layer.
On the other hand, for the out-of-plane deformation $\left(\delta_{y y}\right)$, the map reveals a sharp colour change at the interface with a uniform yellowish area observed in the ferrite layer (Fig. 1(c)). The measured deformation on this image gives a value of $\delta_{y y}=6.7 \pm 0.3 \%$ with respect to the substrate. This value has been found on all observed areas by the HRTEM experiments. Furthermore, no interfacial dislocations are visible on all obtained images from HRTEM suggesting that no plastic relaxation, even partial, occurs. Therefore it is clear that the $\mathrm{CoFe}_{2} \mathrm{O}_{4}$ layer is strongly strained by the substrate.

It is then interesting to calculate the in-plane and out-ofplane components of the strain expected for a completely strained $\mathrm{CoFe}_{2} \mathrm{O}_{4}$ layer. The values of the elastic coefficients, $C_{11}, C_{12}$, and $C_{44}$ are $273 \mathrm{GPa}, 106 \mathrm{GPa}$, and $97 \mathrm{GPa}$, respectively. ${ }^{5}$ We assume no surface relaxation effects due to the thinning along the direction of observation. In the hypothesis of a layer biaxially stressed in the (001) plane because of a lattice mismatch, the in-plane component of strain $\left(\varepsilon_{x x}\right)$ and the out-of-plane component $\left(\varepsilon_{y y}\right)$ are given by the well-known relationships

$$
\begin{gathered}
\varepsilon_{x x}(\%)=\frac{a_{M g A l 2 O 4}-a_{C o F e 2 O 4}}{a_{C o F e 2 O 4}}=-3.68, \\
\varepsilon_{y y}(\%)=-2 \frac{C_{12}}{C_{11}} \varepsilon_{x x}=2.86 .
\end{gathered}
$$

Using $\varepsilon_{y y}$, the out-of-plane lattice parameter of $\mathrm{CoFe}_{2} \mathrm{O}_{4}$ is calculated to be $0.8632 \mathrm{~nm}$.

The in-plane $\delta_{x x}$ and out-of-plane $\delta_{y y}$ deformations of the $\mathrm{CoFe}_{2} \mathrm{O}_{4}$ layer compared to the substrate should thus be $0 \%$ and $6.79 \%$, respectively, for a perfect strained state and equal both to $3.82 \%$ for a perfect relaxed state. Consequently, the comparison between this analysis and our experimental values undoubtedly shows that the $\mathrm{CoFe}_{2} \mathrm{O}_{4}$ layer is perfectly elastically strained on the $\mathrm{MgAl}_{2} \mathrm{O}_{4}(001)$ substrate without notable relaxation. From the in-plane compressive strain $\varepsilon_{x x}$, the in-plane stress component $\sigma_{x x}$ has been calculated and presents a huge value

$$
\sigma_{x x}=\left(C_{11}+C_{12}-\frac{2 C_{12}^{2}}{C_{11}}\right) \varepsilon_{x x}=-10.92 \mathrm{GPa} .
$$

Results are completely different for $\mathrm{CoFe}_{2} \mathrm{O}_{4}$ films grown on $\mathrm{MgAl}_{2} \mathrm{O}_{4}(111)$ (HRTEM image in Figure 2(a)), where a significant modification of the strain state is observed by changing the growth orientation. The HRTEM image (Fig. 2(a)) reveals the high epitaxial quality of the layer, and the strain maps (Figs. 2(b) and 2(c)) indicate a relaxation of the $\mathrm{CoFe}_{2} \mathrm{O}_{4}(111)$ layer in both [010] and [001] directions as a $3.7 \%$ deformation is measured in both cases, which is very close to the theoretical misfit between the ferrite layer and the substrate. This relaxation is accompanied by the presence of a network of misfit dislocations (marked as dashed circles) arranged between 7 and $8 \mathrm{~nm}$ (theoretical value of $7.8 \mathrm{~nm}$ ). The analysis of HRTEM micrographs also shows the presence of APBs (parallel dashed lines in Figure 2(a)). Each of these defects is linked to a dislocation, but all dislocations do not generate an APB.

The different structural properties between the [001] and [111] growth directions have a strong effect on the magnetic 

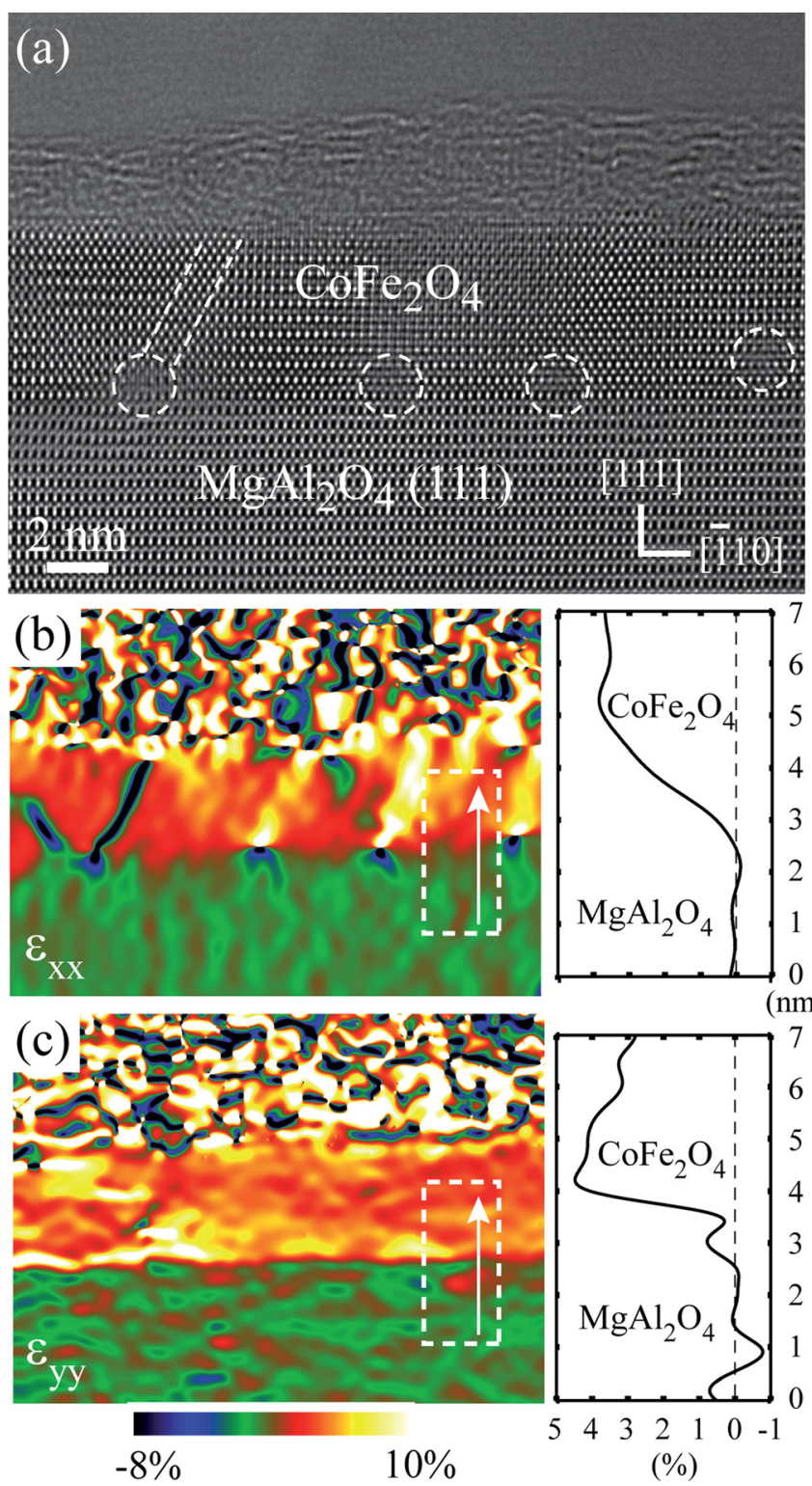

FIG. 2. HRTEM image of a $\mathrm{CoFe}_{2} \mathrm{O}_{4}$ (111) film on $\mathrm{MgAl}_{2} \mathrm{O}_{4}(111)$ (a). Dashed circles indicate dislocations, and the parallel dashed lines mark an antiphase boundary. The geometrical phase analysis is shown for the inplane deformation $\varepsilon_{x x}$ (b) and the out-of-plane deformation $\varepsilon_{y y}$ (c). Profile of the deformation in dashed rectangle is reported for each direction. properties. In-plane hysteresis loops obtained at $300 \mathrm{~K}$ by vibrating sample magnetometry (VSM) after subtraction of the diamagnetic contribution of the substrate are clearly different. The hysteresis loop measured along the [010] inplane direction of the $\mathrm{CoFe}_{2} \mathrm{O}_{4}(001)$ films (Fig. 3(a)) shows large values of both in-plane magnetization $(415 \mathrm{kA} / \mathrm{m}$ at $1.2 \mathrm{~T})$ and coercive field $\left(\mu_{0} \mathrm{H}_{\mathrm{c}} \sim 4700 \mathrm{Oe}\right)$, significantly higher than the values obtained for relaxed thicker films ${ }^{11}$ and very close to the bulk values. For the [111] growth direction, the VSM hysteresis loop along the [-110] in-plane direction presents a completely different behaviour which looks like the one obtained generally for $5 \mathrm{~nm}$-thick ferrite layers, with a strong decrease of the saturation magnetization $(170 \mathrm{kA} / \mathrm{m}$ at $1.2 \mathrm{~T})$ and the coercive field $\left(\mu_{0} \mathrm{H}_{\mathrm{c}} \sim 200 \mathrm{Oe}\right)$ compared to the bulk values. Note that no in-plane anisotropy is observed in both films (not shown). The absence of in-plane anisotropy shows that others factors than the magnetocrystalline anisotropy have a strong effect on the magnetic properties of $\mathrm{CoFe}_{2} \mathrm{O}_{4}$ thin films. Moreover, while similar remanent magnetization values and close coercive fields between perpendicular and parallel directions indicate almost isotropic magnetic properties in the (111) films (Fig. 3(c)), a really strong anisotropy between in-plane and out-of-plane directions is observed in the (001) films (Fig. 3(b)). The isotropic magnetic properties of the $\mathrm{CoFe}_{2} \mathrm{O}_{4}(111)$ films with low magnetization and coercivity values are consistent with the increased presence of numerous APBs in thinner ferrite films as observed in $\mathrm{Fe}_{3} \mathrm{O}_{4}$ layers ${ }^{17,18}$ and confirmed by the HRTEM micrograph presented in Figure 2(a). On the contrary, the pseudomorphic growth along the [001] direction has two effects on the films magnetic properties: it prevents from the formation of APBs allowing to restore bulk-like magnetic properties with high magnetization and coercive field, and it also induces a strong magnetic anisotropy (with magnetization purely in-plane) resulting from the strong in-plane compressive strain.

A study of the different magnetic energies in $\mathrm{CoFe}_{2} \mathrm{O}_{4}(001)$ thin films allows to understand the changes in magnetic properties and the effect of strain. The demagnetizing energy has not to be considered as the magnetization lies in the films plane. The magnetocrystalline energy $\left(\mathrm{E}_{\mathrm{MC}}\right)$ can be computed by the following expression:
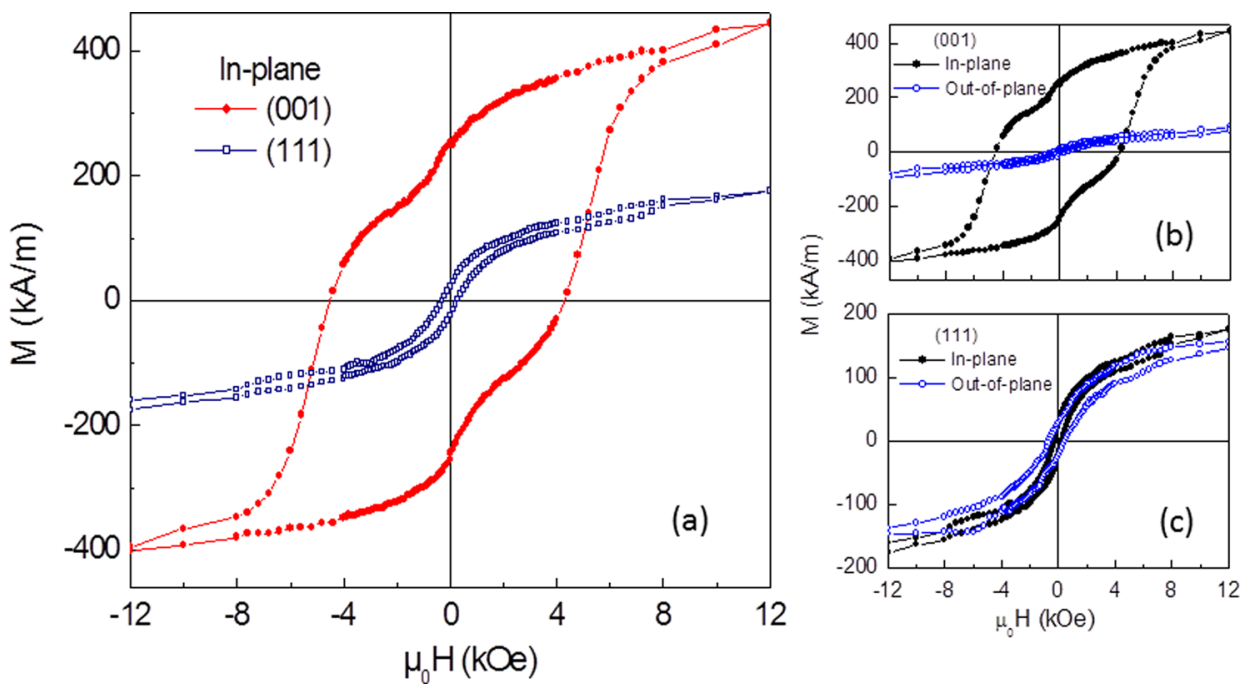

FIG. 3. (a) In-plane magnetic hysteresis loops at $300 \mathrm{~K}$ of a $\mathrm{CoFe}_{2} \mathrm{O}_{4}(5 \mathrm{~nm})$ film grown on $\mathrm{MgAl}_{2} \mathrm{O}_{4}(100)$ and $\mathrm{MgAl}_{2} \mathrm{O}_{4}(111)$. In-plane and out-ofplane hysteresis loops of the film on $\mathrm{MgAl}_{2} \mathrm{O}_{4}(001)$ (b) and $\mathrm{MgAl}_{2} \mathrm{O}_{4}(111)$ (c). In-plane hysteresis loops have been obtained along the [010] direction for $\mathrm{CoFe}_{2} \mathrm{O}_{4}(001)$ and [-110] direction for $\mathrm{CoFe}_{2} \mathrm{O}_{4}(111)$. 


$$
E_{M C}=\frac{K_{1}}{4}\left(\sin ^{2} 2 \theta-1\right)
$$

where $K_{1}$ is the magnetocrystalline constant (between $1 \times 10^{5} \mathrm{~J} \mathrm{~m}^{-3}$ and $\left.4 \times 10^{5} \mathrm{~J} \mathrm{~m}^{-3}\right)^{22,23}$ and $\theta$ the angle between the [100] direction and the magnetization. The maximum variation of $E_{M C}$ is then about $1 \times 10^{5} \mathrm{~J} \mathrm{~m}^{-3}$, when the magnetization is along the [100] or [010] directions. The last energy to take into account is the magnetoelastic energy $\left(\mathrm{E}_{\mathrm{ME}}\right)$ due to the epitaxial strain, expressed as

$$
E_{M E}=-\frac{3}{2} \lambda_{100} \sigma_{x x} \cos ^{2} \theta,
$$

where $\lambda_{100}$ is the magnetostriction coefficient equal to $-590 \times 10^{-6}$ for the [100] directions of $\mathrm{CoFe}_{2} \mathrm{O}_{4}$ (Refs. 5, 22 , and 23) (note that the magnetostriction coefficient is of the same order of magnitude for the [110] direction). Using the in-plane stress $\sigma_{x x}$ value extracted from the geometrical phase method, we found $E_{M E}=-9.66 \times 10^{6} \mathrm{~J} \mathrm{~m}^{-3}$ which presents nearly 2 orders of magnitude of difference compared to $E_{M C}$ and is 10 times larger than the magnetoelastic energy obtained from a $\mathrm{CoFe}_{2} \mathrm{O}_{4}$ layer epitaxially grown on $\mathrm{MgO}(001)$ or $\mathrm{CoCr}_{2} \mathrm{O}_{4}(001) .{ }^{18,22,24}$ From this analysis, we demonstrate that the magnetic properties of $\mathrm{CoFe}_{2} \mathrm{O}_{4}(001)$ layers are strongly affected by the magnetoelastic energy, in accordance with previous results on the effect of $\mathrm{E}_{\mathrm{ME}} .{ }^{5}$ It is worth noticing that this energy term is so strong that the $5 \mathrm{~nm}$ thick layer presents bulk-like properties in the film's plane, on the contrary to measurements on thicker relaxed films. The difference in surface energy between (001) and (111) surfaces, the terminal surface (purely anionic or cationic) and the presence of specific defects of the $\mathrm{MgAl}_{2} \mathrm{O}_{4}(111)$ surface could explain why a non-pseudomorphic growth is observed for the (111) orientation.

In conclusion, $\mathrm{CoFe}_{2} \mathrm{O}_{4}(001)$ and $\mathrm{CoFe}_{2} \mathrm{O}_{4}(111)$ ultrathin films have been grown exactly in the same conditions on $\mathrm{MgAl}_{2} \mathrm{O}_{4}(001)$ and $\mathrm{MgAl}_{2} \mathrm{O}_{4}(111)$ substrates. Significant differences have been observed in the magnetic hysteresis loops for the two crystallographic orientations and explained by the local strain analysis extracted from HRTEM micrographs. The geometric phase method revealed a significant in-plane compressive strain with an out-of-plane deformation for the (001) orientation, while a full in-plane and out-ofplane relaxation was observed for the (111) orientation. The large compressive strain has a clear effect on the magnetic properties of $\mathrm{CoFe}_{2} \mathrm{O}_{4}(001)$ thin films, by strongly increasing the magnetoelastic energy. In addition, the pseudomorphic growth for the (001) direction limits the appearance of APBs, explaining the bulk-like magnetic properties observed. On the contrary, $\mathrm{CoFe}_{2} \mathrm{O}_{4}(111)$ films present a large amount of APBs that are mostly linked to interface dislocations, indicating that the relaxation process occurs from the first steps of the (111) growth. All these results underline the importance of the $\mathrm{MgAl}_{2} \mathrm{O}_{4} / \mathrm{CoFe}_{2} \mathrm{O}_{4}$ interface analysis in order to understand the correlation between structure and magnetic properties of ferrite layers.

The authors would like to thank the METSA network as this work was supported in part by METSA fundings.

${ }^{1}$ L. W. Martin and R. Ramesh, Acta Mater. 60, 2449 (2012).

${ }^{2}$ N. Dix, R. Muralidharan, J. Guyonnet, B. Warot-Fonrose, M. Varela, P. Paruch, F. Sanchez, and J. Fontcuberta, Appl. Phys. Lett. 95, 062907 (2009).

${ }^{3}$ A. V. Ramos, M.-J. Guittet, J.-B. Moussy, R. Mattana, C. Deranlot, F. Petroff, and C. Gatel, Appl. Phys. Lett. 91, 122107 (2007).

${ }^{4}$ G. Hu, J. H. Choi, C. B. Eom, and Y. Suzuki, Mater. Res. Soc. Symp. Proc. 603, 201 (2000).

${ }^{5}$ G. Hu, J. H. Choi, C. B. Eom, V. G. Harris, and Y. Suzuki, Phys. Rev. B 62, R779 (2000).

${ }^{6}$ A. G. Fitzgerald and R. Engin, Thin Solid Films 20, 317 (1974).

${ }^{7}$ J.-B. Moussy, S. Gota, A. Bataille, M.-J. Guittet, M. Gautier-Soyer, F. Delille, B. Dieny, F. Ott, T. D. Doan, P. Warin, P. Bayle-Guillemaud, C. Gatel, and E. Snoeck, Phys. Rev. B 70, 174448 (2004).

${ }^{8}$ A. V. Ramos, J.-B. Moussy, M.-J. Guittet, A. M. Bataille, M. GautierSoyer, M. Viret, C. Gatel, P. Bayle-Guillemaud, and E. Snoeck, J. Appl. Phys. 100, 103902 (2006).

${ }^{9}$ D. Fritsch and C. Ederer, Phys. Rev. B 82, 104117 (2010).

${ }^{10}$ C. Zhong, J. Fang, H. Cao, Q. Jiang, and Z. Dong, Physica B 405, 4283 (2010).

${ }^{11}$ A. V. Ramos, J.-B. Moussy, M.-J. Guittet, M. Gautier-Soyer, C. Gatel, P. Bayle-Guillemaud, B. Warot-Fonrose, and E. Snoeck, Phys. Rev. B 75, 224421 (2007).

${ }^{12}$ W. Huang, J. Zhu, H. Z. Zeng, X. H. Wei, Y. Zhang, and Y. R. Li, Appl. Phys. Lett. 89, 262506 (2006).

${ }^{13}$ F. Rigato, J. Geshev, V. Skumryev, and J. Fontcuberta, J. Appl. Phys. 106, 113924 (2009).

${ }^{14}$ W. Huang, L. X. Zhou, H. Z. Zeng, X. H. Wei, J. Zhu, Y. Zhang, and Y. R. Li, J. Cryst. Growth 300, 426 (2007).

${ }^{15}$ S. Xie, J. Cheng, B. W. Wessels, and V. P. Dravid, Appl. Phys. Lett. 93, 181901 (2008).

${ }^{16}$ T. Dhakal, D. Mukherjee, R. Hyde, P. Mukherjee, M. H. Phan, H. Srikanth, and S. Witanachchia, J. Appl. Phys. 107, 053914 (2010).

${ }^{17}$ A. Lisfi, C. M. Williams, L. T. Nguyen, J. C. Lodder, A. Coleman, H. Corcoran, A. Johnson, P. Chang, A. Kumar, and W. Morgan, Phys. Rev. B 76, 054405 (2007).

${ }^{18}$ S. A. Chambers, R. F. C. Farrow, S. Maat, M. F. Toney, L. Folks, J. G. Catalano, T. P. Trainor, and G. E. Brown, Jr., J. Magn. Magn. Mater. 246, 124 (2002).

${ }^{19}$ S. Matzen, J.-B. Moussy, R. Mattana, K. Bouzehouane, C. Deranlot, F. Petroff, J. Cezar, M.-A. Arrio, P. Sainctavit, C. Gatel, and B. WarotFonrose, Appl. Phys. Lett. 99, 052514 (2011).

${ }^{20}$ Z. Szotek, W. M. Temmerman, D. Ködderitzsch, A. Svane, L. Petit, and H. Winter, Phys. Rev. B 74, 174431 (2006).

${ }^{21}$ M. J. Hÿtch, E. Snoeck, and R. Kilaas, Ultramicroscopy 74, 131 (1998).

${ }^{22}$ Y. Suzuki, G. Hu, R. B. van Dover, and R. J. Cava, J. Magn. Magn. Mater. 191, 1 (1999).

${ }^{23}$ R. M. Bozorth, E. F. Tilden, and A. J. Williams, Phys. Rev. 99, 1788 (1955).

${ }^{24}$ P. C. Dorsey, P. Lubitz, D. B. Chrisey, and J. S. Horwitz, J. Appl. Phys. 79, 6338 (1996). 